\title{
Partial Discharge Type Detection utilizing Statistical Techniques (n-q) and Random Forest Method
}

\author{
Ms. Priyanka Kothoke ${ }^{1}$, Ms. Anupama Deshpande ${ }^{2}$, Mr. Yogesh Chaudhari ${ }^{3}$ \\ \{priyankakothoke250390@gmail.com ${ }^{1}$, mangala.d.2000@gmail.com ${ }^{2}$, yogeshc@nuv.ac.in ${ }^{3}$ \} \\ Research Scholar,Shri J. J. T University, Rajasthan, India ${ }^{1}$, Research Guide, Shri J. J. T University, \\ Rajasthan, India ${ }^{2}$, Assistant Professor, Navrachana University,Vadodara, Gujarat, India ${ }^{3}$
}

\begin{abstract}
Partial Discharge (PD) designs are critical instrument for t,he findings of hi,gh volt,age (HV) protection frameworks. Huma.n specialists can find conceivable protection absconds in different portrayals of th,e PD information. One of the mo,st broadly utilized portrayals is Phase-Resove,d PD (PRPD) designs. So as to guarantee the dependable activity of H.V hardware, it is vit,al to rela,te the noticeable measurable attributes of P.Ds to t,he prope,rties of the imperfection and at last to decide the kind of the deformity. In present work, we hav,e ob-tained and anal,yzed PRPD pattern (n-q) using statistical parame,ters such as mean, stand,ard deviation, variance, skew-ness and kurtosis to de,tect ty,pe of PD \& we have veri,fied the obtain,ed results by prov,iding obta,ined stat-istical para-meters as an in-put for training of Artif,icial Neu-ral Net-work (ANN) in Google colaboratory using Python for Random Forest Method to detect type of discharge such as either void, surface or corona.
\end{abstract}

Keywords: Par,tial Discharge, Phase-resolved, Sta,tistical techniques, Random Forest, Artific,ial Neural Network.

\section{Introduction}

P.D is a limited ele,ctrical release that in part connects the protection among channels and which could conceivably happen nearby a conduit [1]. PDs are major concerned about dielectric materials utilized and to some extent is crossing over the terminals between which the voltage is applied. The protection may comprise of strong fluid, vaporous materi,als or any blend of these. P.D is the primary cause of the electrical maturing and pro-tection brea,kdown of HV elec-trical device. Va-rious well-springs of P.D give di-verse im-pact on pro-tection exe-cution. Subsequently, PD arrangement is sig-nificant so as to ass,ess the severity of the re,lease [2].

The ongoing up-surge of res,earch on PD has been driven to a limited extent by improvement of new quick computerized and PC based methods that can procedure and investigate signals obtained from PD estimations. There is by all accounts a hope that, with adequately refined advanced preparing methods, it should be conceivable not exclusively to increase new knowledge into t,he phy,sical and substance premise of PD marvels, yet in addition to characterize PD 'designs' that can be utilized for distinguishing the qualities of the protection 'absconds' at which the PD occurs [3]. One of the un-doubted focal points of a com-puter aided estimating framework is the capacity to process a lot of data and to transform this data into a reasonable yield [4]. As each imperfection has its own specific debasement instrument, it is imperative to realize the connection between's release designs and the sort of deformity 
[4]. Consequently, pro-gress in the acknowledgment of inside release and th,eir relationship with the sort of deformity is getting progressively significant in quality control in the protecting frameworks [5].

Re,search has been completed in acknowledgment of halfway release sour,ces utilizing factual methods and neural system [6]. We pre-sent a strategy for the mechanized acknowledgment of PRPD designs uti-lizing an A,NN for the genuine characterization task [12]. In o,ur examination, w,e have tried different inside and outside PDs like vo-id, sur-face and co-rona by utilizing factual para-meters, e.g, skew-ness and kur-tosis for $(\varphi-q)$ and $(\varphi-n)$ and me,an, stan-dard de-viation, va,riance, skew-ness and kur-tosis for $(n-q)$ as an underlying advance kno,wn as pre-handling and an unfinished copy is ma,de a,bout the after effects of P.D yype and checked the outcomes by utilizing back prop,agation stra,tegy of ANN using MATLAB tools. [13]

\section{Statistical Parameters}

The significant par,ameters to describe P.Ds are stage edge ' $\varphi$ ', P.D charge extent ' $q$ ' and P.D num,ber of pu-lses ' $n$ '. P.D dissemination designs are made out of these 3 para-meters. Measurable para-meters are utilized for PR example (n.-q).

\subsection{Pro-cessing of data.}

The da,ta which is extracted from source shall involve $\varphi, q, n \&$ voltage ' $\mathrm{V}$ '. The phase determined trends are obtained from this analysis.

\subsubsection{Ana-lysis of $\operatorname{PR}(q-n)$ usi-ng Stat,istical Tech-niques}

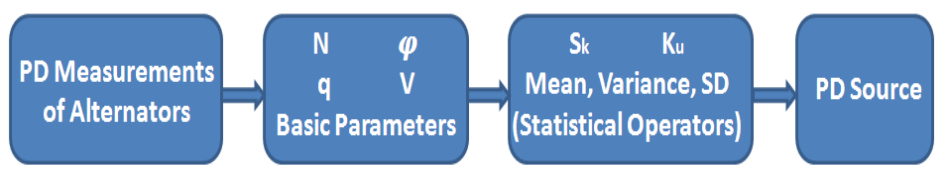

W, here,

Fig. 1. Blo,ck dia-gram of dis-charge anal,ysis for (n-q)

$$
\text { S.D = Stan, dard Deviation } \quad \mathrm{S}_{\mathrm{k}}=\text { Skew-ness } \quad \mathrm{K}_{\mathrm{u}}=\text { Kur-tosis }
$$

St,atistical analysis is applied for the com-putation of several statisti,cal operators. The def,initions of most of these stati,stical operators are described below. The profile of all these dis-crete dis-tribution functions can be put in a general function, i.e., $\mathrm{y}_{\mathrm{i}}=\mathrm{f}\left(\mathrm{x}_{\mathrm{i}}\right)$.

\section{Results and Discussion of Statistical Parameters}

Evaluation using listed parameters includes the identification of un-known P.D patterns by matching them against k,nown P.D patterns including void, surface \&corona. The distinction is rendered by analyzing their mathematical metrics [9]. 


\subsection{Ana-lysis for (n.-q)}

The PR values ( $\mathrm{n}-\mathrm{q})$ are ob-tained for 3 P.D designs: vo,id, sur-face and cor,ona (as described in 3.1.1) and three obscure PD designs: data.1, data.2 and data.3 (as examined in 3.1.3.) [9].

\subsubsection{2-D dis-tribution of n-q for kn-own P.D pa-tterns}

Fig. 2(a), Fig. 2(b), Fi-g. 2(c), Fi,g. 2(d) and F,ig. 2(e) are the n.-q plot of m,ean, stand,ard de-viation, vari,ance, skew-ness and kur-tosis for vo,id release individually.

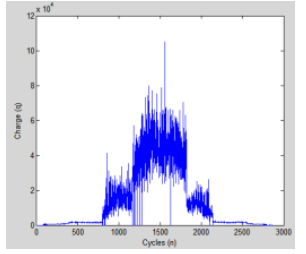

Fig.2 (a) Mea.n plot. (n-q) of void discharge

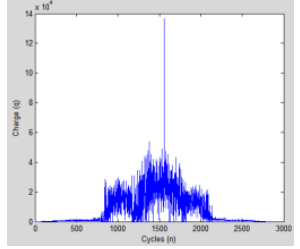

Fi,g.2 (b) Stand.ard de-viation plot (n-q) of void discharge

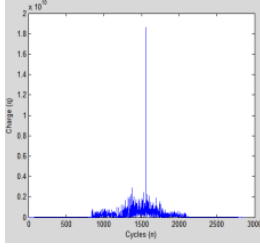

Fig.2 (c)Vari.ance plot (n-q) of void discharge
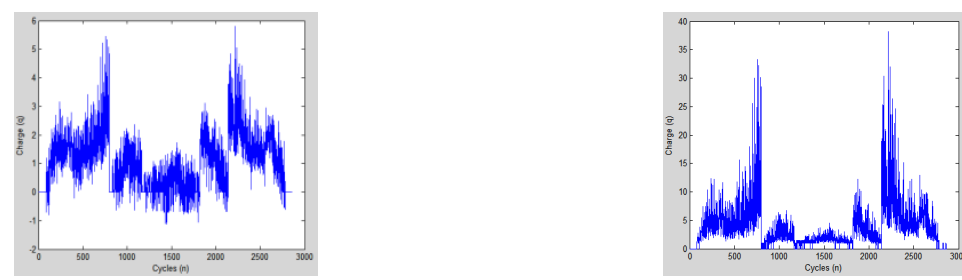

Fig.2 (d) Skew-ness plot (n-q) of voi,d dis-charge $\quad$ Fig.2 (e) Kur-tosis plot (n-q) of vo,id dis-charge

Alluding to Fig. 2 (a), Fig. 2 (b) and Fig. 2 (c) of vo,id release, it very well may be se-en th,ere is a pinnacle happening some place after 15.00 cycle, whic,h is a vo,id release and in F,ig. 2 (d) and F,ig. 2 (e) of skew-ness and kur-tosis, the worth declines at that cy,cle wh,ere pinnacle happens.

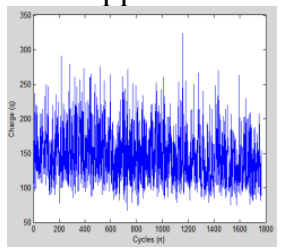

Fig.3 (a) M,ean plot (n-q) of sur-face discharge

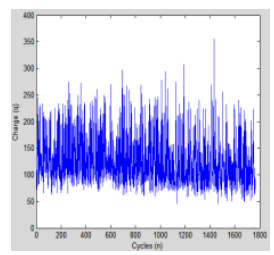

Fig.3 (b) Stan, dard de-viation plot $(n-q)$ of sur-face discharge

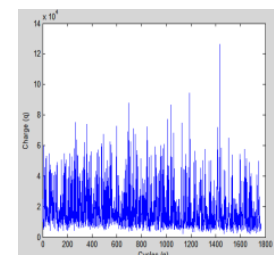

Fig.3 (c) Vari,ance plot (n.-q) of sur-face discharge

In surface release, char-ges are dispersed consiste,ntly over all cy-cles for mean, stan-dard deviation, difference, skew-ness and kur-tosis as appeared.Fig. 4(a), Fig. 4(b), Fig. 4(c), Fig. 4(d) and Fig. 4(e) are the n.-q plot of m,ean, stand.ard de-viation, varia.nce, skew-ness and kurtosis for cor,ona dis-charge res,pectively. 


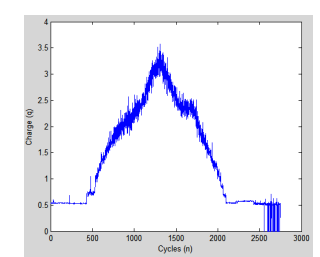

Fig.4(a)Me.an plot (n.-q) of corona dis-charge

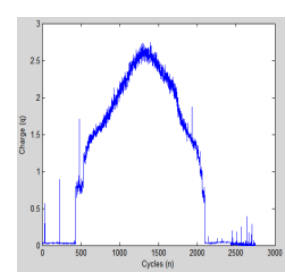

Fig.4(b)Stand.ard de-viation (n-q) of cor.ona discharge

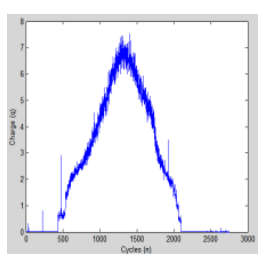

Fig.4(c)Varia.,nce plot (n.-q) of co-rona dis-charge

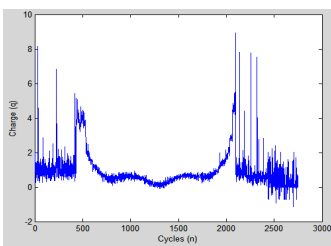

Fig.4(d)Skew-ness plot (n.-q) of cor.ona dis-charge

Fig.4(e)Kur-tosis plot (n-q) of coro.na dis-charge

Alluding to Fig. 4(a), Fig. 4(b) and Fig. 4(c) of crown release, it very well may be seen the char,ges begins happening after 50.0 cycle expanding some place upto 1200 . cycle and afterward diminishing after 2000, cycle, and in Fig. 4(d) and Fig. 4(e) of skew-ness and kur-tosis, the worth declines from 500.0 cycle till 2000.0, cycle.

\subsubsection{2-D distribution of (n-q) for un-known PD patterns}

Fig. 5(a), Fig. 5(b), Fig. 5(c)are the n-q plot of mean, standar.d deviation, fluctuation for datal separately.

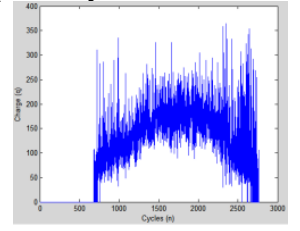

Fig.5(a)Mea,n plot (n-q)of data. 1

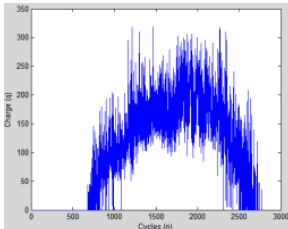

Fig.5(b)Standar,d de-viation plot (nq)of data.1

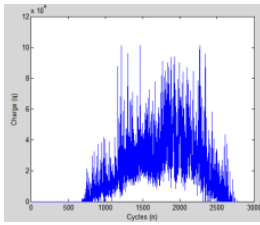

Fig.5(c)Var,iance plot (n-q)of data. 1

In Fig. 5(a), Fig. 5(b), Fig. 5(c), the char,ges are uniformly dis-tributed similar to sur-face discharge. Hence, it can be con-cluded that data.1 is having sur-face dis-charge.Fig. 6(a), Fig.6(b), Fig. 6(c) are the n-q plot of m,ean, standa.rd de-viation, varianc.e, skew-ness and kur-tosis for data.2.

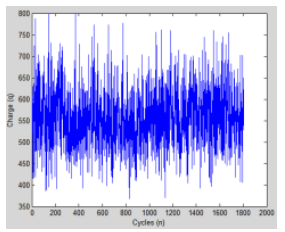

Fig.6(a),Mea,n plot (n-q)of data. 2

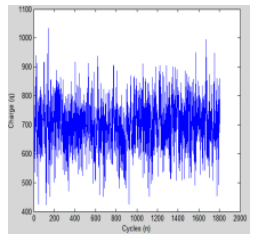

Fig.6(b)Sta.ndard de-viation plot (nq)of data. 2

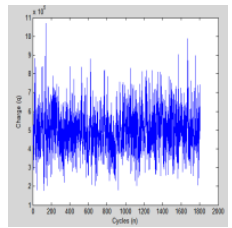

Fig.6(c)Va,riance plot (n-q)of data. 2

In Fig. 6(a), Fig. 6(b), Fig. 6(c), the charges are con,sistently appropriated like surface release. Henceforth, it very well may be reasoned that data2 is having surface release. 


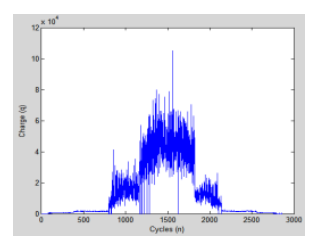

Fig.7(a)M,ean plot (n-q)of data. 3

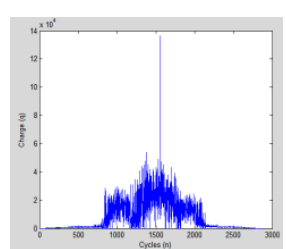

Fig.7(b)Sta,ndard de-viation plot (nq)of data.3

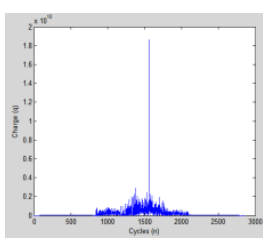

Fig.7(c)Varian,ce plot (n-q)of data.3

Fig. 7(a), Fig. 7(b), Fig. 7(c)are the n-q plot of mean, stan.dard deviation, differe,nce, skewness and kur-tosis for data.3 separately. In Fig. 7(a), Fig. 7(b) and Fig. 7(c), there is an event of top after 150,0 cycle and skew-ness and kurtosis esteem diminishes at that pinnacle which is like void release. Consequently, it tends to be presumed that data3 is void release.

\section{Observations from Statistical Methods}

Fig. 8 is the statistical character,istics of mean, standar.d deviation, varia.nce, ske.wness and kurto,sis of vo,id discharge against data3. Fig. 9(a), Fig. 9(b) are the statisti,cal charac,teristics of mea,n, stan-dard de-viation, vari,ance, skew-ness and kur-tosis of sur-face dis-charge against data. 1 and data. 2 respectively. [14]

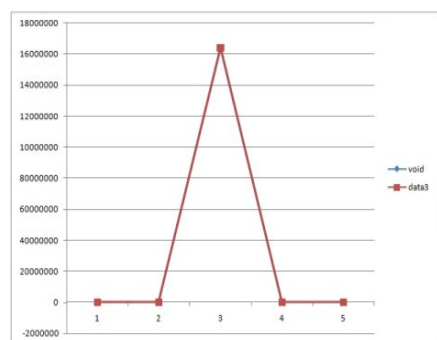

Fig. 8 Statisti,cal Charac,teristics of data. 3 against void discharge

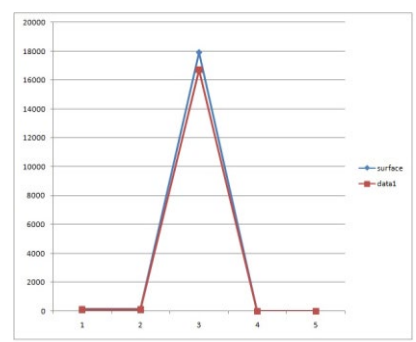

Fig. 9 (a) Statistical charact,eristics of data. 1 against sur,face discharge

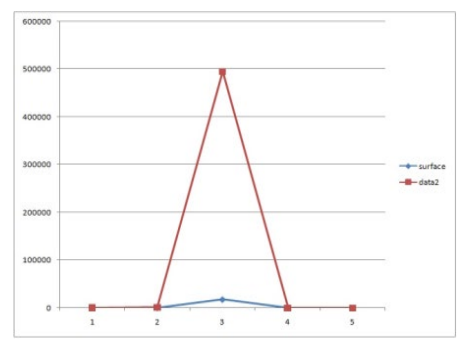

Fig. 9 (b) Statistical

character,istics of data.2 against surface discharge

\section{Discussion on Results of Statistical Parameters}

The following observations are made from the results:

- Plotting stati,stical parameters of void dischar,ge against data.3 in Fig. 8 sh,ows data3 characteris,tics over-laps void charac-teristics, it can be concluded that data. 3 is vo,id disc, harge.

- Similarly, for su-rface discharge, data.1 \& data.2 charac,teristics (Fig. 9(a) and Fig. 9(b)) approx-imately fits sur-face discharge characteri,stics, it can be con-cluded that data. 1 and data. 2 is sur-face dis-charge.

The analysis done from stati,stical parameters are data. 1 is sur,face discharge, data. 2 is surface discharge and data. 3 is v,oid discharge. The analysis using st.atistical parameters can be done for various types of PD discharges. 
Table1: Statistical Method Output

\begin{tabular}{|l|l|}
\hline Un-known data & Par-tial dis,charge Source \\
\hline Data .1 & Surfa,ce \\
\hline Data .2 & Surfa.ce \\
\hline Data. 3 & Voi,d \\
\hline
\end{tabular}

The techniques mentioned are applied the accuracy of 85 percent is obtain. From sta-tistical para,meters, the P.D source cannot be con-cluded accu-rately so it need,s to be ap,plied to others other method such as Random Forest method.

\section{Ran-dom Forest Method}

RF is com-prised of various ch,oice trees. Pro-duce $\mathrm{k}$ choice trees utilizing the Classification And Regression Trees (CART) cal-culation, as ap,peared in Fig.10. [6] The CART calculation utilizes twofold recursive division innovation to develop expectation rules and shows them as parallel trees. It has predominant enemy of commotion execution and is straightforward and utilization. The CART calculation chiefly holds 2 :

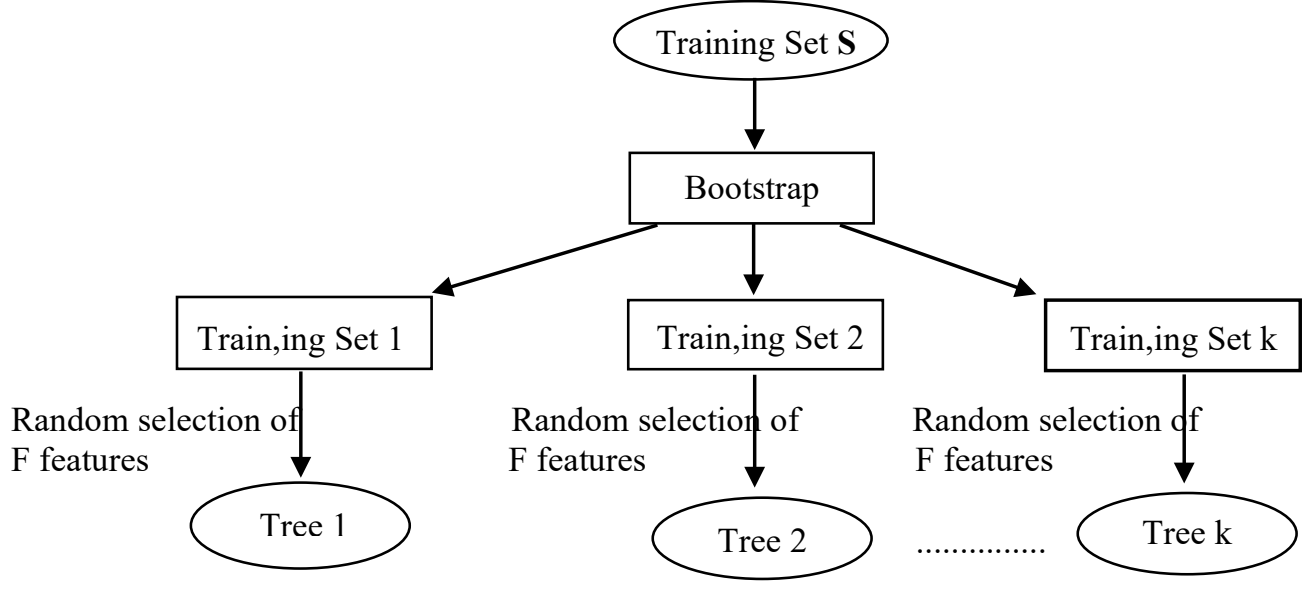

Fig. 10. Build process of RF

Huge considerations: $1^{\text {st }}$, recursively isolating the self-supporting variable space; $2^{\text {nd }}$, using the affirmation data for pruning.

\subsection{Par,tition the in-dependent va-riable space:}

All the mo-del sets are used as root centre points. $\mathrm{X}_{1}, \mathrm{X}_{2} \ldots, \mathrm{X}_{\mathrm{p}} \mathrm{w}$,ere ut,ilized for transferring data to lo-gical factors, and $\mathrm{Y}$ is uti-lized to transfer data to all outer factors. The div, ision va-riable is chosen by the div,ision work and the div,ision edge is re-solved. [7] The moti,vation behind par-titioning the hu,bs is to ceaselessly dim,inish the debase-ment, as appeared in eq. (1) [10] [11]

$$
\mathrm{I}=1-\sum_{k=1}^{c} P_{k}^{2} \quad \ldots \ldots \ldots \ldots . . . \mathrm{eq}(1)
$$

From the eq,uation, $\mathrm{K}$ is kind, $\mathrm{Pk}$ is the degree of the mo-nitoring po,int that has a spot with the kth class. Do above ste,ps till the who,le X space is de-tached to mini,mal squa,re sha,pes which don't cover each an,d every one. [8] 


\subsection{Pru-ning with endo,rsement data:}

Step 1 b,uild tree with mo,st decree,sed corruption level, anyway,y the tree manuf,actured right presen,tly is adequate,ely over-fitting. In order to avoid over-fitting, the t,ree made from its read,iness must be pru-ned with an endors-ement instructive assort-ment, the explana,tion behind which is to get a best pr-uning tree. Truck uses the cost ecce,ntrics $\mathrm{J}$ standard to pruning, and its app,earance is showed up in eq. (2) [11].

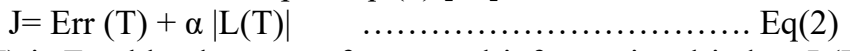

where $\operatorname{Err}(\mathrm{T})$ is E,rr blunder pace of ap,proval inform,ational index, $\mathrm{L}(\mathrm{T})$ is quan-tity of le,aves hubs of tree $\mathrm{T}$, and $\alpha$ is the punish-ment cost for every hub. The pru-ning is halted when the pru-ning gro,uping contains blun,ders inside one stan-dard de-viation of the littlest mistake tree, so, all in all the ideal tree is acquired. The error rate 'E' is articulated as in eq. (3) [11].

$$
\mathrm{E}=\sqrt{E_{\min } \frac{\left(1-E_{\min }\right)}{N}}
$$

Where, $\mathrm{E}_{\min }$ is the mis-take pace of the base blun-der tree, and $\mathrm{N}$ is the quantity of ap,proval in-formational collections.

The procedure of RF implementation is as described follow:

1) 'Extra,cting kpreparing test sets' in the first exa,mple set $\mathrm{n}$ by the Boot-strap technique, the Size of $t$,ests in each preparation set is $n$;

2) Learning indepe,ndently for $\mathrm{k}$ prep,aring sets, produci,ng $\mathrm{k}$ choice tree models. So as to improve the dis-tinction inbetweenchoice trees, the extricated capability,es are arbitrarily chosen. As,sume there are $M$ input fac-tors and arbitrarily extricate $F$ include,esthe division cri-teria of every hub of CART that are randomly chosen in F include sets for all highlights;

3) Combine the after effects of the k CART choice trees to frame the resultant outcome.

\section{Experimen-tal Set up of Random Forest Method}

The implantation uses Google Colab for simplifying as it is open source and user friendly and could be suitably modified for future scope. Five statistical parametersfor both known and unknown discharges are given as an input for the Random Forest (RF) method. [15] [16] [17]

1. Initially, in Google Cola,b laboratory, common model is built for the method. For model building, the obtained statistical para-meters are used for both training and testing.

2. Later, the final processed file (merging all six known and unknown data) is created

3. Finally, this built model of Google Colab (containing RFlibraries) is in py-thon server for creating Graphi,cal User Inter-face (GUI). GUI will display the type of discharge for this (RF) method by entering the listed statistical parameters.

The output (type of discharge) for the RF method will be shown individually as well by entering the input values (statistical parameters) as shown the screenshot in figureFig 11 . The screenshot in Fig 12. shows the output obtained by RF method. To select any one of the two methods by using machine learning model icon is shown in Fig 13. The screenshot in Fig. 14 shows the output by any single method at a time. In Figures, Input data label will be used for entering input values, machine learning models label is used to select one of two methods individually or in group also and prediction label will display the expected output. Table I below is showing the entered input values of five parameters and it is also showing the output 
i.e corona discharge by the RF method. Similarly, output can be shown for corona, surface and void discharges separately by using RF method.

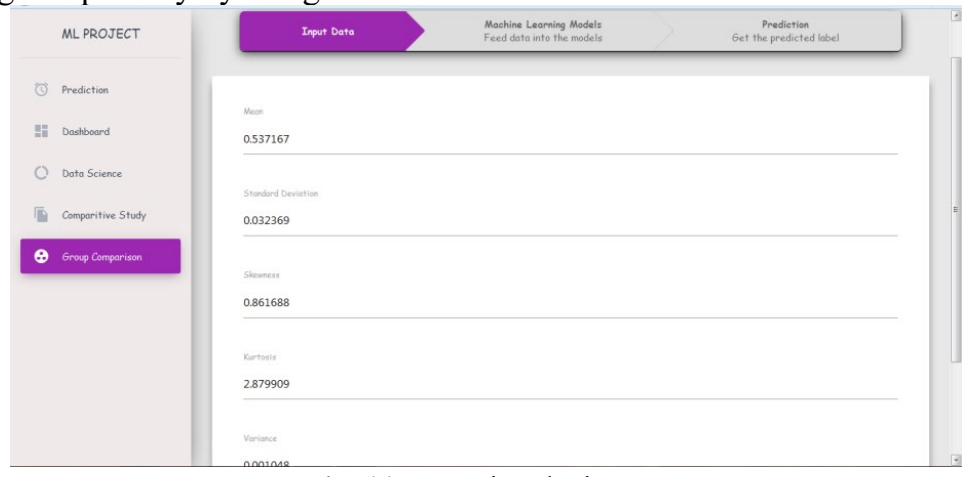

Fig. 11: Entering the input parameters

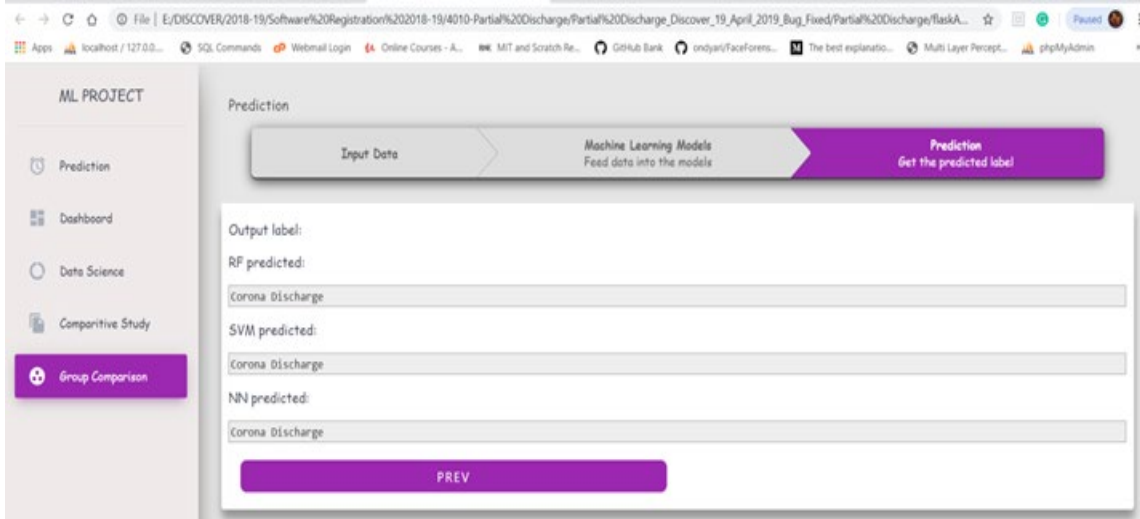

Fig. 12: Group Comparison output

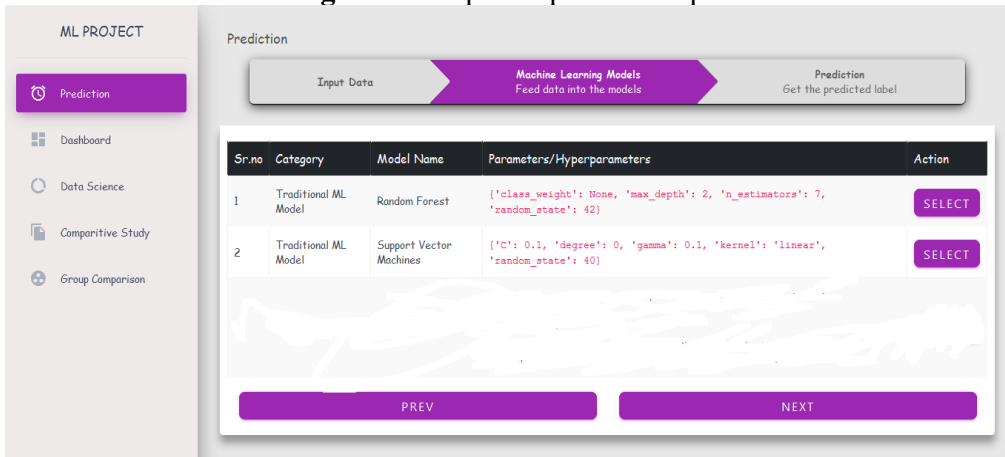

Fig. 13: Selection of method using machine learning model icon 


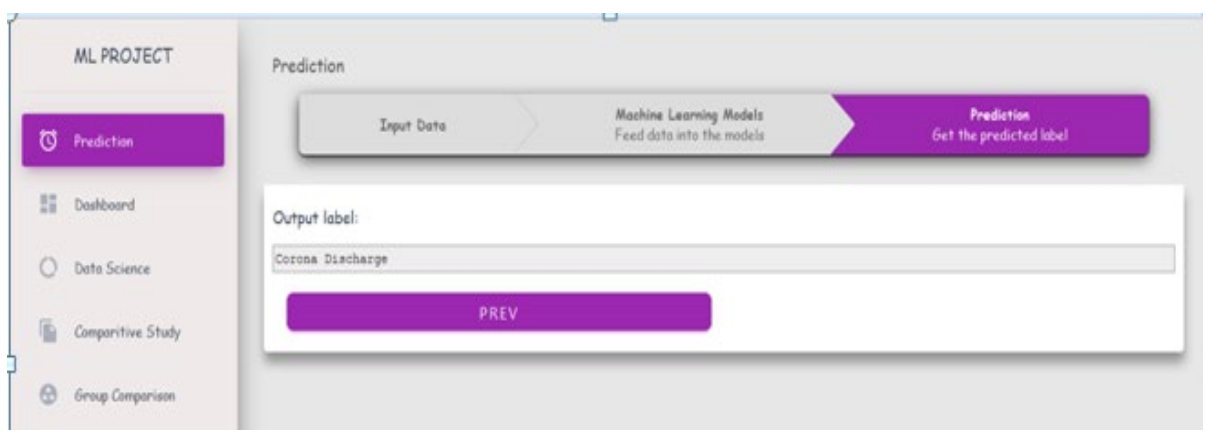

Fig. 14: Output by either of one method viz. is RF method

Table 2: Table showing five entered values by user i.e input values and GUI showing output i.e type of discharge by RF method

\begin{tabular}{|c|c|c|}
\hline Sr.No & Input parameters values & $\begin{array}{c}\text { Output on GUI of group comparison by RF } \\
\text { and SVM method }\end{array}$ \\
\hline 1 & Me,an $=0.5316$ & Co,rona dis-charge \\
\hline 2 & $\begin{array}{c}\text { Stan-dard deviation } \\
0.032169\end{array}$ & Coro.na dis-charge \\
\hline 3 & Skew-ness $=0.861068$ & Cor.ona dis-charge \\
\hline 4 & Kur-tosis $=2.89909$ & Corona dis-charge \\
\hline 5 & Vari,ance $=0.001048$ & Corona dis-charge \\
\hline
\end{tabular}

\section{Conclusion From Random Forest Method}

The results of RF method confirm - Data. 1 and Data. 2 as sur-face dis-charges and Data 3 as void discharge. The results match 100 percent with the statistical method results. The accuracy from RF method is 95\%.Self-Organizing Map (SOM) method of ANN could segregate the exact percentages of discharge types occurring in insulation if multiple discharges are present i.e 52\% surface discharge, 45\% void discharge and 3\% corona discharge in the combined unknown data. This result showed an accuracy of $89 \%$.From BPM method of ANN got the results of Data. 1 and Data. 2 as sur-face dis-charges and Data.3 as void dis-charge. The percentage of res,ults is accuracy of $84.48 \%$ by BPM method of ANN. [15] [16] [17]

Table 3: Output by two methods individually and in group comparison

\begin{tabular}{|l|l|}
\hline Un-known data & Par-tial dis-charge Sou.rce \\
\hline Data .1 & Sur-face \\
\hline Data .2 & Sur-face \\
\hline Data. 3 & Voi-d \\
\hline
\end{tabular}

The designed models for both methods and the results are confirmed accurately for predicting the type of PD. Use of Google colaboratory for SVM gives accurate results and moreover is helpful to reduce the error to zero at faster rate.As a final point, it can be concluded as: for detection of type of partial discharge, we suggest to use SVM method individually and group comparison of RF and SVM methods. In case, group comparison shows different discharge 
types at same time,use SOM to detect exact percentage of discharges occurring in insulation is recommended.

\section{Future Scope}

Fut,ure sc,ope of this re-search is to b,uild hard-ware model for any hig.h vol-tage equipment in which pro-gramming of all m,ethods explain,ed above viz: Sta-tistical method, SV.M, AN.N and R.F is in-built. The ra,w data from P.D sen-sor can be en-tered into the mo-del for pre-proce,ssing and its out-put gives type of dis-charge acc,urately.

\section{References}

[1] Manual: MICAMAXX ${ }^{\mathrm{TM}}$ plus - Partial Discharge Basics

[2] Journal article: M. G. Danikas, "The Definiti,ons Used for Partial Dis,charge Phenomena," IEEE Trans. Elec. Insul., Vol. 28, pp. 1075-1081, 1993.

[3] Journal article: N.C. Sahoo, M. M. A. Salama, R. Bartnikas, "Trends in Part,ial Discha,rge Pattern Classification: A Survey", IEE,E Transactions on Dielectrics and Electrical Insulation, Vol. 12, No. 2; April 2005.

[4] Journal article: E. Gulski, J. Smit,h, R. Brooks, "Partial Dischar,ge Databases for Diagnosis Support of HV Components", IEEE Symposium on Electrical Insulation, pp. 424-427, 1998

[5] Journal article: E. Gulski and F. H. Kre,uger, "Computer-aided recognition,n of Discharge Sources," IEEE Transactions on Electrical Insulation, Vol. 27 No. 1, February 200,2.

[6] Journal article: E. Gulski and A. Kriv,da, "Neural Networks as a Tool for Recognition of Partial Discharges", IEEE Transactions on Electrical Insulation, Vol. 28 No.8, December 1993.

[7] Journal article: F. H. Kreuger, E. Gulski and A. Krivda, "Classification of Partial Discharges", IEEE Transactions on Electrical Insulatio,n, Vol. 28 No. 6, December1993.

[8] Article: C. Chang and Q. Su, "Stat,istical Characteristics of Partial Discharges from a Rod-Plane Arrangement"Center for Electrica,l Power Engineering, Department of Electrical \& Computer System Engineering, Monash University, Clayton VIC 3168 Australia

[9] Journal article: Priyanka Kothoke, Namrata Bhosale, Amol Deshpande, Dr. Alice Cheeran(2013), "Analysis of Partial Discharge using Phase-Resolved (n-q) Statistical Techniques", International Journal of Engineering Research and Applications ISSN: 2248-9622, Vol. 3, Issue 3, May-Jun 2013, pp.1317-1323.

[10] Journal article: Christian Cac-hin, Hans JiirgWiesmann, "PD Recogni,ion with Kno,wledge-based Pre-processing and Neu,ral Net,works", IE.EE Trans,actions on Die,lectrics and El,ectrical In,sulation Vol. 2, Issue 4, August 1995.

[11] Conference proceeding paper: Sh,ijun Wang, Chang Pinga,ndGuobinXue. Transf,ormer Partial Dischar.ge Patter.n R,ecognition Base,d on Ra-ndom Forest, IOP Conf. Series: Jou,rnal of Physics: Con-ference Series (2019) 0620251176.

[12] Journal article: B. Freisleben, M. Hoof, R. Patsch, -Using Counter Propagation Neural Networks for Partial Discharge Diagnosisll, International Journal of Neural Computing and Applications, Volume 7, Issue 4, pp. 318-333, 1998.

[13] Journal article: R. Candela, G. Mirelli, R. Schifani, -Partial Discharge Recognition by Means of Statistical and Fractal Parameters and a Neural Networkll, IEEE TDEI, Vol. 7, No. 1, pp. 87-94, 2000.

[14]Journal article: Yogesh R. Chaudhari, Namrata R. Bhosale, Priyanka M. Kothoke(2013), "Composite Analys,is of Phase Resol,ved PD Pattern,s using Sta,istical Te,chniques", International Jo, urnal of Mo,dern Engi,neering Res, earch (IJMER) Vol. 3, Issue. 4, pp-1947-1957, 2013. 
[15] Journal article: Priyanka Kothoke, Dr.Anupama Deshpande, Yogesh Chaudhari, "A Literature Review of methods used for Partial Discharge Type Detection and its Improvised Techniques;", International Journal of Innovative Research in Science, Engineering and Technology(IJIRSET),Vol. 08, Issue 07, July 2019.

[16] Conference proceeding paper:Priyanka Kothoke, Dr.Anupama Deshpande, Yogesh Chaudhari, "Examination and Determination of Partial Discharge Source utilizing SOM and BPM Techniques of ANN", Conference on Engineering Systems Design and Optimization(CESDO-2020), inclusion into Elsevier and Scopus.

[17] Conference proceeding paper:Priyanka Kothoke, Dr.Anupama Deshpande, Yogesh Chaudhari, "Investigation and Determination of PD source utilizing SVR and RF", International Conference on Inventive Computation Technologies (ICICT-2020), inclusion into IEEE Xplore and Scopus. 